\title{
Translinguagem em foco: o percurso avaliativo de estudantes do PEC-G em aulas de Português como língua adicional
}

\author{
Translanguaging in focus: the assessment journey of PEC-G students \\ in Portuguese as an additional language classes
}
El translingüismo en el foco: el trayecto evaluativo de los estudiantes del PEC-G en las clases de portugués como lengua adicional

\author{
Rafaela Santos de Souza ${ }^{1}$ (i) https://orcid.org/0000-0003-0306-386X \\ Lívia Márcia Tiba Rádis Baptista² (iD https://orcid.org/0000-0001-7137-5473
}

\begin{abstract}
RESUMO: Tendo como base os resultados gerados a partir de uma pesquisa qualitativa de cunho etnográfico, assim como as contribuições dos estudos sobre práticas translíngues (CANAGARAJAH, 2013a; ROCHA; MACIEL, 2015)/translinguagem (GARCÍA; WEI, 2014) e avaliação em contextos multilíngues (SHOHAMY, 2001, 2011), o objetivo desse artigo é o de problematizar o processo de avaliação ao qual os sujeitos plurilíngues são submetidos. Para tanto, retomamos parte de nossa pesquisa que tratou do processo de avaliação centrado nas práticas translíngues empreendidas por estudantes africano(as) integrantes do PEC-G (Programa de Estudantes-Convênio de Graduação), participantes de aulas de português. Dentre os meios de avaliar, a produção escrita ganha mais evidência, pois ainda que, não raro, se atenha a dimensão estritamente linguística e formal, permite-nos que, se observadas as práticas translíngues, os sujeitos expressem suas identidades nesses espaços e, sendo assim, foi esse nosso foco no estudo. Partimos, portanto, da ideia da relevância de contemplarmos as realidades dos sujeitos sociais nos processos avaliativos contemporâneos. Diante dos resultados obtidos, neste artigo buscamos (re)pensar meios possíveis para avaliar estudantes em aulas de português como língua adicional, considerando as práticas linguageiras e como essas impactam o âmbito educacional.
\end{abstract}

PALAVRAS-CHAVE: Português como língua adicional. Avaliação. Produção escrita.

ABSTRACT: Based on the results obtained in a qualitative ethnographic research, as well as studies about translingual practices (CANAGARAJAH, 2013a; ROCHA; MACIEL, 2015)/ translanguaging (GARCÍA; WEI, 2014) and assessment in multilingual contexts (SHOHAMY, 2001,

\footnotetext{
1 Mestre em Língua e Cultura pelo Programa de Pós-Graduação em Língua e Cultura da Universidade Federal da Bahia (UFBA).E-mail: rafaelas.souza@outlook.com

2 Doutora em Linguística pelo IEL, Unicamp. Professora Associada IV da Universidade Federal da Bahia. Docente permanente do Programa de Pós-Graduação em Língua e Cultura da mesma instituição. E-mail: liviarad@yahoo.com
} 
2011), the aim of this article is to problematize the assessment process to which plurilingual subjects are submitted. To do so, we resume part of our research that dealt with the assessment process focusing on the translingual practices performed by students from African countries who are members of the PEC-G (Exchange Program for Undergraduate Students), participating in Portuguese classes. Among the means of assessment, the written production becomes more evident, because although it is often restricted to a strictly linguistic and formal dimension, it allows us, if we observe the translingual practices, for the subjects to express their identities in these spaces and, thus, this was our focus in the study. Therefore, we start from the idea of the relevance of considering the realities of social subjects in contemporary assessment processes. In face of the results obtained, in this article we tried to (re)think possible ways to assess students in Portuguese as an additional language classes, considering the language practices and how they impact the educational field.

KEYWORDS: Portuguese as an additional language. Assessment. Written production.

RESUMEN: A partir de los resultados generados a través de una investigación etnográfica cualitativa, así como de los estudios sobre prácticas de translenguaje (CANAGARAJAH, 2013a; ROCHA; MACIEL, 2015)/translingüismo (GARCÍA; WEI, 2014) y evaluación en contextos multilingües (SHOHAMY, 2001, 2011), el objetivo de este artículo es problematizar el proceso de evaluación al que se someten los sujetos plurilingües. Para ello, retomamos una parte de nuestra investigación en la que nos ocupamos del proceso de evaluación centrado en las prácticas de translenguaje realizadas por los estudiantes africanos miembros del PEC-G (Programa de Estudiantes-Convenio de Graduación), que participaban en las clases de portugués. Entre los medios de evaluación, la producción escrita adquiere mayor relieve, pues, aunque muchas veces pueda restringirse a una dimensión estrictamente lingüística y formal, nos permite, si se observan las prácticas translingüísticas, que los sujetos expresen sus identidades en estos espacios, de modo que este fue nuestro foco en el estudio. Por lo tanto, dada la relevancia de tener en cuenta las realidades de los sujetos sociales en los procesos de evaluación contemporáneos. En vista de los resultados obtenidos, en este artículo buscamos (re)pensar posibles formas de evaluar a los estudiantes en las clases de portugués como lengua adicional, considerando las prácticas lingüísticas y cómo estas impactan el entorno educativo.

PALABRAS CLAVE: Portugués como lengua adicional. Evaluación. Producción escrita.

\section{Introdução}

Moita Lopes (2013) chama atenção para o fato de as sociedades estarem sendo alteradas de forma rápida, pois estamos em um mundo de fluxos e os sujeitos se movimentam por entre fronteiras podendo estas serem tanto nacionais como as de comunicação. Em vista disso, é preciso que a seara educacional esteja de acordo com os movimentos e com o fluxo das pessoas, por isso segue a necessidade de (re)pensarmos o contexto do ensino-aprendizagem de línguas, já que a partir desses espaços os sujeitos se constituem no mundo. Dentro desse contexto, precisamos reconhecer a complexidade de ensinar-aprender na contemporaneidade, devido às dificuldades, tais como a falta de valorização dos(as) profissionais que compõem o ambiente educacional; as mudanças, tanto as relacionadas às práticas de linguagens de sujeitos que integram a sala de aula, 
quanto às concepções de ensino e às práticas pedagógicas e as mudanças ocasionadas pela globalização da comunicação e da tecnologia.

Diante do cenário mencionado, investigações na linha da Linguística Aplicada surgem como meios de (re)pensar os contextos com foco nos sujeitos sociais e suas práticas de linguagem. Esse deslocamento na forma de se produzir conhecimento em sala de aula impõe igualmente a revisão dos métodos avaliativos para as práticas de sujeitos que (re)negociam sentidos em mais de uma língua, de maneira que os métodos englobam a complexidade das práticas de linguagens nas quais sujeitos plurilíngues se envolvem em zonas de contatos interculturais (PRATT, 1991). Sendo assim, é importante que as estratégias avaliativas empregadas pelos(as) professores(as), no caso de alunos(as) plurilíngues, estejam de acordo com a realidade das práticas desenvolvidas por esses sujeitos, já que, na maioria das vezes, o uso do repertório vasto de alunos(as) de contextos multilíngues é desconsiderado no ambiente educacional, tal como enfatizam García e Wei (2014) e Canagarajah (2011a).

À vista disso, Shohamy (2011) salienta que as avaliações pautadas em uma visão de língua homogênea são meios de propagar e defender a ideologia monolíngue, contrária ao que assinalamos no cenário descrito. Nesse âmbito, um dos processos avaliativos de grande importância é o da produção escrita. As produções escritas nos espaços de ensino-aprendizagem são algumas das possibilidades que os sujeitos plurilíngues têm de produzir e (re)negociar sentidos na(s) língua(s) que estão aprendendo. A escrita é o ato de compartilhamento no qual os indivíduos participantes do processo vão interagir e criar sentidos no espaço em que estão inseridos. $O$ ato de produzir textos consiste ainda em uma das formas por meio das quais os sujeitos acessam o repertório linguístico que dispõem para (re)negociar sentidos através da linguagem.

Considerando o exposto, este artigo é resultante de um recorte de nossa pesquisa de mestrado, na qual buscamos entender em que se consistiam práticas de translinguagem dos sujeitos denominados de plurilíngues, e como essas práticas poderiam ser consideradas nas aulas de Português como língua adicional (PLA), assim como a constituição para a (re)construção da avaliação. Tomamos aqui PLA, pois consideramos que a língua aprendida passa a ser um recurso a mais a ser adicionado aos repertórios linguísticos dos sujeitos. No caso em tela, essa concepção de língua adicional enfatiza que nossos(as) participantes da pesquisa estavam/estão aprendendo a língua 
em contexto de imersão, no Brasil, e, mais especificamente, em Salvador, podendo acessar seus repertórios para suas experiências linguísticas diariamente.

Com relação ao cenário da pesquisa, esse foi o subprograma PROEMPLE (Programa Especial de Monitoria de Português como Língua Estrangeira), desenvolvido no ano de 2014, um curso multinível, não dividindo esses(as) estudantes em níveis de aprendizagem, já que o propósito é diferente das demais línguas ${ }^{3}$. Este subprograma faz parte do programa mais amplo intitulado PROFICI (Programa de Proficiência em Língua Estrangeira para Estudantes e Servidores da UFBA), implementado no ano de 2012 pela Universidade Federal da Bahia. Os(as) participantes da pesquisa são alunos(as) estrangeiros(as) vinculados(as) ao programa PEC-G (Programa de Estudantes-Convênio de Graduação), que faziam/fazem parte das aulas de Português do PROEMPLE/PROFICI. Esses(as) estudantes estrangeiros(as) que compõem as salas de aula do PROEMPLE têm o objetivo de estudar em um dos inúmeros cursos de graduação ofertados pelas IES (Instituições de Ensino Superior) brasileiras, porém, para que isso seja possível, uma das exigências é que tenham a comprovação e aprovação no exame de proficiência CELPEBRAS (Certificado de Proficiência em Língua Portuguesa para Estrangeiros) e, a partir do resultado nesse exame, os(as) estudantes terão a oportunidade de se matricular no curso escolhido durante o processo de inscrição (realizada em seu país de origem), de acordo com o Decreto no 7.948 que rege as normas do programa PEC-G (BRASIL, 2013).

Os(as) participantes da pesquisa foram sete estudantes da turma do PROEMPLE, do ano de 2020, uma turma formada por dez estudantes, sendo oito desses(as) de países do continente africano e dois de países da América Central. Só participaram sujeitos de países multilíngues e todos os nomes aqui apresentados foram escolhidos pelos sujeitos da pesquisa. Os instrumentos utilizados para a geração dos dados foram um questionário semiestruturado, anotações de campo, que ajudaram no desenvolvimento da pesquisa, e as produções escritas realizadas nas aulas de português.

Tabela 1 - Sujeitos de pesquisa ${ }^{4}$

\begin{tabular}{|c|c|c|c|c|}
\hline NOME FICTÍCIO & IDADE & GÊNERO & FORMAÇÃO & PAÍS \\
\hline Kim & 24 anos & Masculino & segundo grau & Guiné Equatorial \\
\hline
\end{tabular}

\footnotetext{
${ }^{3}$ Como explicado no texto, o subprograma PROEMPLE faz parte do programa maior que é o PROFICI e dentro desse programa, existem outros subprogramas responsáveis por diferentes línguas que são ensinadas, a saber, alemão, espanhol, francês, inglês e italiano.

4 Essa pesquisa contou com a aprovação do Comitê de Ética, CAAE: 26817119.0.0000.5531.
} 
Translinguagem em foco: o percurso avaliativo de estudantes do PEC-G em aulas de Português como língua adicional

\begin{tabular}{|c|c|c|c|c|}
\hline Neymar & 19 anos & Masculino & segundo grau & Guiné Equatorial \\
\hline Popcorn & 31 anos & Masculino & superior & Benin \\
\hline Preciosa & 20 anos & Feminino & segundo grau & Gabão \\
\hline Rajulein & 24 anos & Masculino & segundo grau & Mali \\
\hline Reina & 19 anos & Feminino & segundo grau & Guiné Equatorial \\
\hline Wendy & 21 anos & Feminino & segundo grau & Guiné Equatorial \\
\hline
\end{tabular}

Fonte: Elaborada pelas autoras.

Convém observar que as produções narrativas escritas faziam parte das aulas de português do PROEMPLE; eram atividades não pontuadas, visto que o curso não está desenhado para priorizar resultados atrelados exclusivamente à quantificação e notas. $\mathrm{A}$ ideia do curso, portanto, consiste em focar na (re)construção das práticas linguísticas a partir das experiências que esses sujeitos se inserem no dia a dia. Chamamos atenção para o fato de as produções narrativas desses(as) estudantes serem de grande importância, uma vez que os sujeitos analisam o ambiente em que estão inseridos para acessar seus repertórios e (re)construir suas práticas linguísticas. Essas produções são pontos de partida para refletirmos criticamente sobre o processo de ensino-aprendizagem de línguas e a forma como podemos avaliar os sujeitos sociais.

\section{Globalização e Superdiversidade}

A mobilidade das pessoas, associada com a era da globalização, faz com que a comunicação torne-se cada vez mais rápida e intensa. Kumaravadivelu (2006) apresenta informações da United Nations Report on Human Development, destacando que tanto a distância temporal como a espacial estão diminuindo. Neste sentido as fronteiras estão desaparecendo ou se fragilizando, e é possível ver as trocas ocasionadas por esse advento; podendo essas serem positivas, mas também negativas, como salienta Milton Santos (2001), quando alerta sobre a globalização perversa, desencadeada por ações desenfreadas que caracterizam atitudes hegemônicas. Diante desse panorama, são apontadas três facetas que geram grandes efeitos sociais:

[...] A primeira [...] à possibilidade de deslocamentos físicos, facilitados pelo desenvolvimento dos meios de transporte, como exemplificam as ondas migratórias em escala global. A multiplicidade de rotas geográficas e formas diferenciadas de inserção sociocultural [...] incrementam uma experiência de multiculturalismo e hibridação, especialmente nas grandes 
metrópoles, onde o convívio com alteridades culturais se intensifica, geralmente, de forma desigual e discriminatória. [...] A segunda [...] a possibilidade de vivências de uma 'multiterritorialidade' associada aos avanços, no campo informacional, da internet e da cibercultura territórios que, ao ressignificarem e ampliarem nossos horizontes espaçotemporais e comunicacionais, catapultam as possibilidades de outra espécie de roteiro [...] A tal movimento se associa um terceiro, a expansão vigorosa dos meios de produção cultural, o que potencializa as possibilidades tanto de contato com alteridades quanto de (re)construção de significados (FABRÍCIO, 2013, p. 149-150).

Com a contínua transitoriedade dos sujeitos desencadeando na superdiversidade dos espaços, as práticas linguageiras e as (re)construções identitárias não podem mais ser alicerçadas na ideia de território fechado, mas sim interpretadas como (re)negociações que vão para além de espaços fixos e restritos. É possível perceber as transformações que compõem os espaços que tornam-se superdiversificados, a partir das categorias migratórias. As categorias de diferenciação mais conhecidas dentro dos estudos migratórios, como nacionalidade, língua, religião, etnicidade, se diversificam e fragmentam as zonas de sedimentação em interação com motivos variados, padrões e processos de integração (DIAS; PINTO, 2017).

Dentro desse panorama que forma a sociedade contemporânea, encontramos uma diversificação dentro da diversidade já existente. Essa composição na estrutura social chamamos de "superdiversidade", termo cunhado por Vertovec (2007) e defendido, posteriormente, por outros autores (BLOMMAERT; RAMPTON, 2011). Esse termo é proposto, também, no sentido da emergência de novos padrões de migração e considerando-se as combinações decorrentes dessas caracterizações para a produção de novas posições sociais de hierarquia. Neste cenário, portanto, irrompem novos padrões de preconceito, desigualdade, segregação e racismo, assim como novas experiências de contato (VERTOVEC, 2019).

Desta maneira, a superdiversidade não é somente uma simples característica das sociedades com uma vasta diversidade cultural e identitária, nesses contextos superdiversos. Considerando o exposto, como uma forma de conceitualizar as constituições sociais da contemporaneidade, neste trabalho nós compartilhamos o conceito proposto por Duboc e Fortes (2019, p. 3), quando essas autoras defendem que:

[...] parte de uma compreensão mais fluida sobre língua/linguagem, aprendizagem e comunidade em que se expandem e legitimam ambientes formais e não formais de aprendizagem de uma língua. Na medida em 
que os sujeitos contemporâneos transitam por diferentes redes de relações e comunidades e na medida em que, simultaneamente, vão construindo sentidos no encontro e na manipulação de diferentes modos semióticos, a ideia de repertório vai se tornando cada vez menos associada a uma comunidade supostamente homogênea e permanente, para ser entendida como resultado das subjetividades e das trajetórias de vida.

Portanto, como uma forma de conceitualizar as constituições sociais da contemporaneidade, apresentamos essa definição dos espaços superdiversos, pois dentro desses contextos em que existem as interações locais e reais a partir da linguagem, podemos nos deparar com o bilinguismo/multilinguismo/translingualismo. 0 conceito de multilinguismo ora defendido o reafirma como parte de um processo dialógico, através do qual diferentes línguas estão em contato, já que a junção levaria a um reconhecimento positivo de/sobre outros sujeitos como enfatiza Rutar (2014). Conforme essa autora, existiria uma abertura para diferentes construções de significados, e, desta forma, o multilinguismo vem fazer parte dos territórios, os sujeitos inseridos nesses espaços estão em um momento em que línguas-culturas diversas circulam, encontram-se, entrelaçam-se e tornam as práticas linguísticas multifacetadas e híbridas.

Importa entender, de acordo com essa ótica, que o multilinguismo foca nas práticas linguísticas dos sujeitos e em como esse foco tem impacto na construção da vida dos sujeitos, ou seja, o foco não recai no número de línguas faladas nos espaços, mas sim na necessidade de se entender as (re)construções desenvolvidas a partir dos contatos. Um exemplo desse fato é apresentado por Jacquemet (2005, p. 264): ${ }^{5}$

[...] Grupos diaspóricos e locais recombinam suas identidades mantendo presença simultânea em uma multiplicidade de locais e participando de redes eletivas espalhadas por territórios transnacionais. Essas identidades recombinantes são baseadas em multi-presença, multilinguismo e engajamentos políticos/sociais descentrados. Quero argumentar que as lentes que geralmente adotamos ao olhar para a linguagem devem ser significativamente alteradas para acomodar fenômenos comunicativos produzidos por identidades recombinantes, mesmo que esses fenômenos não tenham ordem gramatical e sintática, ou não possam sequer ser reconhecidos como parte de um único código padronizado. ${ }^{6}$

\footnotetext{
5 Todas as traduções são de responsabilidade das autoras.

6"Diasporic and local groups alike recombine their identities by maintaining simultaneous presence in a multiplicity of sites and by participating in elective networks spread over transnational territories. These recombinant identities are based on multi-presence, multilingualism, and decentered political/social engagements. I want to argue that the lenses we usually adopt in looking at language must be significantly altered to accomodate for communicative phenomena
} 
Quando refletimos sobre essa acepção de práticas linguísticas, na realidade, encontramos conceitos que integram as realidades linguísticas dos sujeitos e solidificam os ambientes superdiversos, estando, assim, inseridos na perspectiva contemporânea dos estudos linguísticos. Logo, essas práticas linguageiras são denominadas translanguaging /translingualismo (GARCÍA, 2009; GARCÍA; WEI, 2014) ou translingual practice/práticas translíngues (CANAGARAJAH, 2013a, 2013b; ROCHA; MACIEL, 2015).

Esse é um ato que sujeitos bilíngues realizam, acessando diferentes características linguísticas ou vários modos do que é descrito como linguagem autônoma, para potencializar a comunicação (GARCÍA, 2009). Neste sentido, acreditamos que os(as) participantes da pesquisa são sujeitos plurilíngues, entretanto, devido à imposição das interações sociais e dos espaços em que estão inseridos, esses sujeitos, ainda em suas práticas comunicativas, moldam-se aos meios e fazem uma separação linguística, se for necessário, para o desenvolvimento da interação. Sendo monolíngues em duas ou mais línguas.

Neymar7: Eu falo espanhol, francês, português e um pouco de inglês. Eu não uso essas línguas em todos os contextos nem com todas as pessoas, eu sou uso quando estou falando com pessoas que falam essa língua.

Reina: Não uso essas línguas em todos os contextos nem com todas as pessoas. Dependendo do contexto/situação ou pessoas, eu falo uma língua ou outra.

Concordamos com a concepção de bilinguismo defendida por García (2009), visto que essa autora alerta para o fato de que as línguas se mesclam, ou seja, são usadas ao mesmo tempo para um propósito comunicativo e não quando um sujeito aprende duas línguas e passa a nomeá-las como primeira ou segunda, pois, a partir do momento que tal ocorre, esse sujeito passa a ser monolíngue em duas línguas, já que fará uso das línguas separadamente. Algumas vezes, como já apresentado, os sujeitos estão inseridos no processo de hibridização linguística, mesmo não sabendo o porquê dessa "mistura" ou tentando explicá-la. A essa forma híbrida das interações, denominamos práticas translíngues.

Popcorn: [...] eu falo outros idiomas além do francês. Só porque me permite expressar-me mais facilmente e há palavras ou expressões em

produced by recombinant identities, even if these phenomena lack grammatical and syntactical order, or cannot even be recognized as part of a single standardizable code."

${ }^{7}$ Os trechos das respostas e os trechos das produções escritas estão como o original. 
nossos idiomas que não podemos traduzir para o francês ou estas palavras ou expressões não existem em francês. Por vezes, ou melhor, comumente, misturamos o francês e nossos idiomas no meio de uma conversa.

Translinguagem, portanto, é "[a] capacidade dos falantes [plurilíngues] de transitar entre as línguas, tratando as diversas línguas que formam seu repertório como um sistema integrado [...]"8 (CANAGARAJAH, 2011a, p. 401). Já Kimura e Canagarajah (2018) explicam o termo translinguagem, considerando o prefixo "trans". Os autores destacam duas principais premissas do termo: a primeira dessas é a de reconhecer que a comunicação transcende línguas individuais; e, a segunda, a de entender os diversos recursos semióticos, não restritos às palavras, como gestos, por exemplo, na construção dos propósitos comunicativos para dar significados. Já para Leroy (2018, p. 73), esse prefixo significa "[..] ir além do construto monolíngue, estanque e não dinâmico das linguagens". Ainda neste sentido, de acordo com Canagarajah (2011b), a translinguagem ajuda-nos a assumir orientações que sejam específicas para os sujeitos plurilíngues, considerando a competência desses sujeitos.

O termo translíngue concebe as relações linguísticas em termos mais dinâmicos. Os recursos semióticos do próprio repertório ou da sociedade interagem mais estreitamente, tornam-se parte de um recurso integrado e se aprimoram mutuamente. As linguagens se interligam de forma transformadora, gerando novos significados e gramáticas $^{9}$ (CANAGARAJAH, 2013a, p. 8, grifo nosso).

Deste modo, esses sujeitos podem ser chamados de plurilíngues considerando o uso da língua, nessa perspectiva híbrida, pois lançam mão de diferentes recursos linguísticos e semióticos, para que seus propósitos comunicativos sejam alcançados e, desta forma, dar sentido ao mundo que fazem parte. Portanto, a translinguagem permite que os(as) falantes plurilíngues, usuários(as) de um repertório linguístico vasto, no espaço social, possam reunir diferentes dimensões de experiências, partindo de suas histórias pessoais, das suas ideologias, até a capacidade cognitiva e física para desempenhar a (re)construção de significados para serem vividos (WEI, 2011).

\footnotetext{
8 "The ability of [...] speakers to shuttle between languages, treating the diverse languages that form their repertoire as an integrated system $[\ldots]^{\prime \prime}$

9 "The term translingual conceives of language relationships in more dynamic terms. The semiotic resources in one's repertoire or in society interact more closely, become part of an integrated resource, and enhance each other. The languages mesh in transformative ways, generating new meanings and grammars."
} 


\section{Processo avaliativo e a produção escrita de sujeitos plurilíngues}

Os espaços de interação levam os(as) participantes das práticas a posicionaremse em relação a situações que ocorrem no dia a dia, e, por isso a (re)construção e as (re)negociações das identidades, dos sujeitos inseridos, nesses lugares de troca são de grande relevância para a formação do aqui e agora, das práticas reais. Contudo, para que tal possa acontecer, é importante que participantes no processo da escrita posicionem-se criticamente, por meio do incremento do pensamento crítico. Daí, portanto, a importância do letramento e do letramento crítico, a qual nos remetemos a seguir.

O letramento, de acordo com Soares (2009, p. 18), pode ser considerado como "[...] o resultado da ação de ensinar ou de aprender a ler e escrever: o estado ou a condição que adquire um grupo social ou um indivíduo como consequência de ter-se apropriado da escrita". Neste sentido, o processo do letramento é tão parte do nosso dia a dia que Kleiman (1995) chama atenção para o fato de que nas sociedades industrializadas e tecnológicas, a escrita está presente em todos os lugares. Desse modo, um exemplo tão rotineiro e muito familiar (para os grupos que a autora chama de letrados) é a ida ao supermercado, pois é criada uma lista do que será comprado e no local, nós nos deparamos com datas de validade, cartazes informando promoções, temos formas de fazer as contas, então essa é uma maneira de agir no meio e se comunicar.

Desta forma, o letramento aparece como um meio de ajudar e guiar os sujeitos na (re)construção das práticas sociais, de maneira crítica, a partir da escrita, com o propósito de proporcionar mudanças no entorno. Neste viés, o letramento crítico, segundo alguns estudiosos (DUBOC; FERRAZ, 2011; SHOR, 1999), constitui um meio de não só propiciar essas mudanças, mas também de questionar o que é dito ou imposto. Assim, o letramento crítico "envolve questionar o conhecimento recebido e a experiência imediata com o objetivo de desafiar a desigualdade e desenvolver uma cidadania

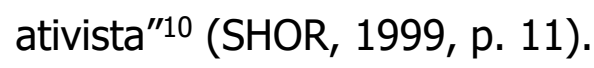

Como defendem Cope e Kalantzis (2009), estamos em meio a uma mudança profunda, e cada vez mais devemos ser exigentes ao invés de permanecermos como developing an activist citizenry". 
meros espectadores. Com o letramento, os(as) alunos(as) utilizam-se das práticas de leitura e escrita, para interpretar e questionar ideologias impostas e, a partir disso, são capazes de usar o processo de escrita para a mudança social. O texto, então, passa a ter um papel de importância no processo educativo.

Lembramos ainda que Koch (2003) alerta que a conceitualização de texto existe em consonância com a concepção de língua defendida; logo o conceito de texto que atravessa a relação de interação dos(as) estudantes com a construção de sentido é considerado uma relação dialógica:

[...] na concepção interacional (dialógica) da língua, na qual os sujeitos são vistos como atores/construtores sociais, o texto passa a ser considerado o próprio lugar da interação e os interlocutores, como sujeitos ativos que - dialogicamente - nele se constroem e são construídos. Desta forma há lugar no texto, para toda uma gama de implícitos, dos mais variados tipos, somente detectáveis quando não se tem, como pano de fundo, o contexto sociocognitivo dos participantes da interação (KOCH, 2003, p. 17, grifo nosso).

Assim, todo o construto de um texto vai representar uma espécie de ponte lançada entre um indivíduo e os outros, pois, como afirma Bakhtin (2014, p. 117, grifo do autor), "[...] toda palavra comporta duas faces [...] tanto pelo fato de que procede de alguém, como pelo fato de que se dirige para alguém. Ela [a palavra] constitui justamente $o$ produto da interação do locutor e do ouvinte". Tendo como base os pensamentos de Bakhtin, Souza (2011, p. 53) enfatiza que

[...] as palavras revelam-se e ganham significações nas interações concretas, quando socialmente compartilhadas, em diálogo entre dois ou mais indivíduos inseridos no fluxo da comunicação diária. A palavra é sempre dirigida a outro sujeito; é sempre resposta a alguém em função da suposição do horizonte social informado por aspectos partilhados tanto pelo falante como pelo ouvinte. É na interação que linguagem se coloca em movimento e provoca ações de respostas em relação à palavra.

Partindo dessa ideia, Antunes (2005) defende que, consoante a perspectiva da interação, escrever só pode ser uma atividade cooperativa, na qual os sujeitos agem em conjunto para interpretação de um determinado sentido. Neste viés, Dilli, Schoffen e Schlatter (2012, p. 172) concebem "[...] as práticas sociais como construídas na ação conjunta dos participantes em uma situação de comunicação com um determinado propósito negociado por eles no aqui-e-agora". Ilustramos com esses trechos de 
produções escritas para que seja possivel perceber as (re)negociações que os sujeitos empreendem na medida que se envolvem em práticas linguageiras.

Neymar: Desde criança sempre gostei de brincar, minha mãe dizia que parecia que eu estava plugado ou algo parecido porque nunca parava de me mexer ou brincar o tempo todo. Quando criança eu tinha uma grande variedade de jogos que me permitiam me entreter por um tempo, já que naquela época eu não tinha muitas coisas tecnológicas para me entreter além da televisão ou de um brinquedo. Passei a maior parte da minha infância sozinha, pois só tinha irmãs e às vezes não queria jogar seus jogos, até que alguns anos depois nasceu e cresceu meu irmão mais novo, com quem eu começaria a compartilhar meus jogos. Dentre todos os jogos que eu podia fazer naquela época, meu favorito era sempre jogar futebol, sozinho ou com meus amigos ou primos.

Popcorn: Por um lado, eu estava feliz por ir a uma aventura, conhecer outro país, aprender uma nova língua e descobrir outras culturas. E o mais maravilhoso foi que eu estava tão entusiasmado como uma pulga, entusiasmado porque finalmente iria conhecer Salvador de Bahia. Uma cidade sobre a qual eu tanto ouvira falar e pela qual até me apaixonei, sem saber que um dia eu caminharia em seu solo. Lembro que durante a constituição dos arquivos eu escolhi Salvador duas vezes. Por outro lado, eu estava triste porque ia deixar minha mãe e minhas irmãs sozinhas, especialmente com a saúde de minha mãe falhando. Esse era o meu único medo.

Preciosa: Os participantes tomam distância, formando um retângulo entre eles. O terceiro participante fará a seqüência de movimentos no retângulo de elástico. A cada seqüência bem-sucedida, o elástico sobre um nível: dos tornozelos para os joelhos, daí para as coxas e então para os quadris Se não houver duas pessoas para servir de apoio para o elástico, vale a pena usar cadeiras como apoios. Uma de minhas brincadeiras da infância foi imaginar ser modelo e organizar os desfiles.

Rajulein: Eu vivenciei minhas experiências de ensino médio numa escola pública. Fizemos parte das primeiras gerações daquela escola pois era bem recente na época. Lá, havia regulamentos sérios para o bom funcionamento do espaço escolar. No começo, tivemos um diretor bem rígido que se importava muito com a educação da gente, ele até vigiava o uso correto do uniforme dos alunos. No primeiro ano, encontrei novos colegas em que, outros se tornaram amigos de verdade. Eu passava quase todo meu tempo com meu amigo preferido, ele era inteligente, bem educado e até agora, gosto dele. Gostávamos muito de corrigir os colegas quando eles erravam.

Diferente da fala, tida como uma ação espontânea, a atividade escrita é monitorada e um pouco livre, pois existem escolhas estratégicas para a construção do texto, como enfatiza Canagarajah (2011a). Já que as produções escritas são práticas sociais, em que os(as) alunos(as) produzem sentido através da linguagem, os sujeitos 
plurilíngues, que fazem uso de um repertório linguístico vasto, (re)negociam esses sentidos produzidos de acordo com suas práticas de linguagem.

Nas produções escritas, os sujeitos performam suas identidades e coconstroem sentido através das palavras, permitindo que seja possível entender o que deseja ser dito. A discussão sobre as produções escritas ganha corpo, pois quando se trata da oralidade, o modo de avaliar pode ser "um pouco mais livre", ao ser relacionado com a ideia de língua escrita. Alguns(mas) profissionais da área da educação, do ensino de línguas, não raramente, fixam-se em regras linguísticas voltadas a um ideal homogeneizante do que é a língua. As palavras de Shohamy (2001) sobre o poder dos instrumentos avaliativos é direcionado, aqui, para a escrita, pois a autora diz que esses instrumentos, associados às produções escritas, violam princípios e valores democráticos, já que esses testes vêm das organizações que controlam o poder e tendem a definir o conhecimento apropriado, negando a existência de outros.

Entretanto, nas produções escritas, a ideia de correção age de forma mais incisiva; as produções tornam-se mais engessadas, e, muitas vezes, os sujeitos plurilíngues não encontram espaço para a prática híbrida da linguagem, pois existe a crença acerca do que é certo e do que é errado, como afirmou Shohamy (2001). Diante disso, Canagarajah (2013a) argumenta que, enquanto os estudos que investigam a oralidade e conversação só crescem, a escrita ainda se atém a concepção normativa da língua, por mais que o autor foque no ensino de língua inglesa, podemos deslocar esse pensamento para entender o processo avaliativo de outras línguas, nesse caso o português.

Para rebater essa visão e esse engessamento, a orientação translíngue entende a hibridização linguística como um ato de criação e (re)negociação dos sujeitos. Levando em conta a liberdade de expressão de forma híbrida, apresentamos a afirmação de Souza (2011) sobre esse conceito. A autora explana que os discursos essencialistas atrelados à identidade ou à pureza cultural são ameaçados, já que as possibilidades de (re)negociações, conflitos e alianças são mostradas e estão presentes nos arranjos que se formam entre os diversos entrecruzamentos culturais.

Considerando o mencionado antes, esclarecemos que em nosso estudo nos importou enfatizar como os sujeitos inseridos nesse processo (re)criam, (re)constroem sentidos, identidades e performam na escrita, tudo isso através das práticas linguísticas. A hibridização linguística dentro do texto é o que Canagarajah (2011a) denomina como 
um codemeshing, ou seja, é a realização do ato translíngue nas produções textuais. Apresentamos alguns trechos de produções escritas, a seguir, nas quais os sujeitos mesclam seus repertórios linguísticos para (re)criar sentidos, porém, vale ressaltar que aqui nos interessa refletir sobre a concepção atrelada ao sentido e para tanto destacar o que esses sujeitos querem dizer. Outro ponto relevante a citar diz respeito ao fato de os sujeitos transitarem por línguas, os sujeitos (fora do espaço de investigação) usam nomenclaturas para indicar a língua que estão acessando em determinado momento.

Kim: As diferenças de pano era só para poder diferenciar quem era da família do noivo e quem era da família da noiva. Na culinária cada família cozinhava um prato típico da sua tribo entre outros pratos como; envuelto de cacahute (envolto de amendoim), molho de dendê, molho de quiabo.

Reina: Isso aconteceu ao começo do segundo trimestre do primer ano do ensino médio. A genge sempre ficava cansada porque viemos de celebrar o Natal e o Ano Novo, porém tinhamos que seguir com as aulas. Como nosso colégio é bem católico, pertence ao grupo dos Salesianos, a festa mais grande de nossa escol é a festa do Don Bosco. Cada ano celebrábamos a festa no día 31 de Janeiro, día de sua morte para comemorá-lo. Nesse día fazíamos muitas atividades, primero nós íamos à missa, cantávamos e também orávamos. Depois tinhamos a gran gincana, onde fazíamos atividades esportivas em grupos para obter pontos e ganhar a festa. O seguinte era um gran desfile de cada aula com uma bandeira pessoal e finalizávamos com uma atuação, já seja canto, baile ou teatro. Cada ano as instruções mudabam. Mas nesse ano, nossa aula estava tendo muitos examens e trabalhos que entregar pelo qual sempre adiavamos o dia de ensaio, até que só ficava um dia para que pudéssemos fazer algo e percebemos que nada sairía. Então, simplesmente decidimos não fazer nada.

Wendy: Primeiramente vamos cortar a carne e depois lavar-la com água quente, para tirar toda a suzera, é muito importante que os pedaços da carne sejam menores, porque assim será mais facil a absorção dos ingredientes que vamos adicionar para fervér-la, é muito importante lavar a carne con água quente, porque se não fazemos isso a suzera da carne pode aparecer após de você ter colocado a carne junto con os ingredientes e estragar o sabor de seu prato, então senpre lave sua carne com água quente $[. .$.

A importância, então, desse processo para os(as) estudantes é fazer com que eles(as) percebam suas práticas e suas estratégias como formadoras de identidade e que essas atitudes dentro do texto têm uma grande relevância, tanto para o ambiente de sala de aula, como para a criação de uma consciência crítica e social.

Como salienta Canagarajah (2011a), existem boas razões para o uso das 
Translinguagem em foco: o percurso avaliativo de estudantes do PEC-G em aulas de Português como língua adicional

estratégias que os(as) estudantes desenvolvem nas produções escritas, pois os(as) professores(as) podem fazer uso dessas para criar práticas de ensino. Neste sentido, como enfatiza o mesmo autor, estudantes plurilíngues "[...] trazem de suas casas e comunidades conhecimentos que são valiosos para eles mesmos e para os outros"11 (CANAGARAJAH, 2011a, p. 415). Entretanto, ainda que a avaliação multilíngue esteja disponível, existe uma imposição linguística, e as línguas são vistas separadamente como destacam García e Wei (2014).

O espaço defendido é aquele que possibilite as práticas translíngues, entendendo esse processo como complexo e enriquecedor para formação dos sujeitos e suas performances através da língua. Então, o translanguaging space/espaço translíngue é fundamental para os sujeitos plurilíngues, não apenas por causa do uso de recursos linguísticos múltiplos que contribuem para formação e transformação das vidas dos inseridos nessa prática, mas também pelo fato de que, nesse espaço, esses sujeitos, através de suas práticas translíngues, podem criar seu próprio poder de transformação (WEI, 2011).

Neste sentido, compreendemos que a sala de aula é um espaço privilegiado para que os sujeitos plurilíngues possam criar o seu próprio poder de transformação através das práticas linguageiras. Reforçamos esse pensamento trazendo as palavras de Dilli, Schoffen e Schlatter (2012) a respeito de que a sala de aula é, na verdade, um espaço em que é possível praticar diferentes usos da língua, e, ao mesmo tempo, ser participante das mais variadas práticas sociais, no nosso caso, práticas sociais atreladas à escrita. Enfatizamos, então que

A sala de aula é um poderoso espaço de negociação de políticas. As pedagogias praticadas e textos produzidos em sala de aula podem reconstruir políticas estabelecidas. De fato, a sala de aula já é um espaço de políticas; toda vez que os professores insistem em uma variedade uniforme de língua ou discurso, estamos ajudando reproduzir ideologias monolingualistas e hierarquias linguísticas ${ }^{12}$ (CANAGARAJAH, 2006, p. 587).

\footnotetext{
11 "[...] bring from their homes and communities funds of knowledge that are valuable for themselves and others."

12 "The classroom is a powerful site of policy negotiation. The pedagogies practiced and texts produced in the classroom can reconstruct policies ground up. In fact, the classroom is already a policy site; every time teachers insist on a uniform variety of language or discourse, we are helping reproduce monolingualist ideologies and linguistic hierarchies."
} 
Isto posto, destacamos, conforme Garcia e Wei (2014), a pedagogia translíngue tem um potencial para desenvolver discursos sofisticados, uma compreensão mais profunda dos textos, assim como a produção de textos muito mais complexos, focando em uma avaliação que seja mais autêntica e que seja muito mais significativa para os(as) estudantes, fazendo com que ocorra o questionamento das desigualdades, e a inclusão das vozes dos(as) alunos(as) que tiveram suas práticas linguísticas minoritarizadas.

\section{Conclusão}

No recorte apresentado ao longo deste trabalho, retomamos parte de nossa pesquisa de mestrado, orientada pela perspectiva da translinguagem como uma forma de (re)pensar os contextos de ensino-aprendizagem de aulas de PLA (dentre outras línguas) para estudantes de espaços multilíngues. Reconhecemos, para tanto, as práticas linguageiras empreendidas por esses sujeitos diariamente; notamos que essas práticas se tornam complexas à medida em que esses sujeitos vão (re)negociando os sentidos a partir de onde estão no aqui e agora. Sendo assim, acreditamos ser importante que os(as) profissionais que constituem o âmbito educacional lidem de maneira crítica com as diferenças em sala de aula, para que os(as) estudantes possam levar suas práticas linguísticas e identitárias para além dos muros que compõem os espaços de ensino.

Entretanto, a inquietação mais pulsante na pesquisa se deu quanto ao questionamento voltado para o processo de avaliação que os sujeitos que compõem os espaços multilingues foram apresentados ao longo de suas vidas. Os meios de avaliar, embora importantes, tendem a não permitir que os sujeitos expressem suas identidades, focando somente em notas e nos resultados das produções, e em uma ideia de quantidade, desconsiderando as experiências que os sujeitos trazem em suas bagagens relacionadas às vivências linguísticas. Esse fator se torna mais impactante em produções escritas que serão avaliadas, uma vez que na e para a escrita ainda parecem servir de parâmetro um ideal linguístico que proporciona a manutenção de uma ideia de monolinguismo. Essa concepção, por sua vez, desconsidera que podem ser acionados diversos repertórios pelos sujeitos e esses podem se refletir e estar presentes nos textos produzidos por esses sujeitos e podem apontar indícios de como esses sujeitos lidam com suas experiências entre as línguas e com as línguas, inclusive, aquela outra, a adicional, que está se somando ao seu repertório.

Por fim, cabe notar que não consiste uma tarefa fácil essa mudança de foco, porém 
não podemos desistir de buscar meios de contemplar sujeitos que possam utilizar seus repertórios linguísticos de maneira confiante em produções avaliativas, sem serem penalizados ou até ter uma associação atrelada a uma noção de erro, já que não segue o ideal de homogeneização linguística. O ponto é pensar na heterogeneidade dos sujeitos, nas (re)construções identitárias de pessoas que transitam por entre espaços diversos e trazem suas experiências para sala de aula, não sendo enquadradas em um ideal forçado e controlador. Desta forma, ressaltamos a necessidade de orientar o trabalho com a produção de texto por um caminho construtivo, de modo que os(as) alunos(as) reflitam sobre suas práticas e tragam suas experiências com suas línguas para o processo de ensino-aprendizagem. Contudo, para que tal aconteça é preciso que os direcionamentos que guiam as práticas do ambiente educacional sejam orientados com base em um viés crítico para proporcionar uma transformação social, pois quando as aulas de línguas permitirem essas transições, tanto professores(as) como alunos(as) poderão vivenciar o bilinguajamento defendido por Mignolo (2000).

\section{Referências}

ANTUNES, Irandé. Lutar com palavras. coesão e coerência. São Paulo: Parábola Editorial, 2005.

BAKHTIN, Mikhail. Marxismo e filosofia da linguagem. Tradução Michel Lahud e Yara Frateschi Vieira. São Paulo: Hucitec, 2014.

BLOMMAERT, Jan; RAMPTON, Ben. Language and superdiversity. Diversities, [s. I.], v. 13, n. 2, p. 1- 22, 2011. Disponível em: www.unesco.org/shs/diversities/vol13/issue2/art1. Acesso em: 30 maio 2021.

BRASIL. Decreto n. 7.948, de 12 de março de 2013. Dispõe sobre o Programa de Estudantes-Convênio de Graduação - PEC-G. Diário Oficial da União, Brasília, DF, 13 de março de 2013. Disponível em: http://www.planalto.gov.br/ccivil_03/_Ato20112014/2013/Decreto/D7948.html. Acesso em: 20 maio 2021.

CANAGARAJAH, Suresh. The place of world englishes in composition: pluralization continued. College Composition and Communication, Urbana, v. 57, n. 4, p. 586-619, 2006. Disponivel em: https://www.jstor.org/stable/20456910. Acesso em: 10 maio 2021.

CANAGARAJAH, Suresh. Codemeshing in academic writing: identifying teachable strategies of translanguaging. The Modern Language Journal, Madison, v. 95, n. 3, p. 401-417, 2011a. Disponível em:

https://onlinelibrary.wiley.com/toc/15404781/2011/95/3. Acesso em: 10 maio 2021. 
CANAGARAJAH, Suresh. Translanguaging in the classroom: emerging issues for research and pedagogy. Applied Linguistics Review, [s. I.], v. 2, p. 1-27, $2011 \mathrm{~b}$.

CANAGARAJAH, Suresh. Transligual practice: global englishes and cosmopolitan relations. New York: Routledge, 2013a.

CANAGARAJAH, Suresh. Negotiating translingual literacy: an enactment. Research in the Teaching of English, Urbana, v. 48, n. 1, p. 40-67, 2013b. Disponivel em: https://www.researchgate.net/publication/282178615 Negotiating Trans lingual Litera cy An Enactment. Acesso em: 10 maio 2021.

COPE, Bill; KALANTZIS, Mary. "Multiliteracies": new literacies, new learning. Pedagogies, [s. I.], v. 4, n. 3, p. 164-195, 2009. Disponível em: https://www.researchgate.net/publication/242352947 Multiliteracies New Literacies N ew Learning. Acesso em: 20 junho 2021.

DIAS, Ana Luiza Krüger; PINTO, Joana Plaza. Ideologias linguísticas e regimes de testes de língua para migrantes no Brasil. RBLA, Belo Horizonte, v. 17, n. 1, p. 61-81, 2017. Disponível em: https://www.scielo.br/j/rbla/a/fykQYK4zDrDtHdGRrfMyXQN/?lang=pt. Acesso em: 05 maio 2021.

DILLI, Camila; SCHOFFEN, Juliana Roquele; SCHLATTER, Margarete. Parâmetros para a avaliação de produção escrita orientados pela noção de gêneros do discurso. In: SCHOFFEN, Juliana Roquele et al. (org.). Português como língua adicional: reflexões para a prática docente. Porto Alegre: Bem Brasil, p. 169-197, 2012.

DUBOC, Ana Paula Martinez; FERRAZ, Daniel Mello. Letramentos críticos e formação de professores de inglês: currículos e perspectivas em expansão. Revista $X$, Curitiba, v. 1 , p. 19-32, 2011. Disponível em: https://revistas.ufpr.br/revistax/article/view/23056. Acesso em: 30 maio 2021.

DUBOC, Ana Paula Martinez; FORTES, Olívia Bueno Silva. Superdiversidade, linguagem e sociedade: questões em curso. Entrevista com Jan Blommaert e Massimiliano Spotti (Tilburg University). Educação e Pesquisa, São Paulo, v. 45, p. 1-23, 2019. Disponível em: https://www.scielo.br/j/ep/a/MmCjWGy5tvS6q3v75YgNWJn/. Acesso em: 15 maio 2021.

FABRÍCIO, Branca Falabella. A "outridade lusófona" em tempos de globalização: identidade cultural como potencial semiótico. In: MOITA LOPES, Luiz Paulo. $O$ português no século XXI: cenário geopolítico e sociolinguístico. São Paulo: Parábola, p. 144-168, 2013.

GARCÍA, Ofelia. Education, multilingualism and translanguaging in the 21st century. In: SKUTNABBKANGAS, Tove et al. (org.). Social justice through multilingual education. Bristol: Multilingual Matters, p. 140-158, 2009.

GARCÍA, Ofelia; WEI, Li. Translanguaging: language, bilingualism and education. Londres: Palgrave Pivot, 2014.

JACQUEMET, Marco. Transidiomatic practices: language and power in the age of globalization. Language and communication, Oxford, v. 25, n. 3, p. 257-277, 2005. 
Translinguagem em foco: o percurso avaliativo de estudantes do PEC-G em aulas de Português como língua adicional

Disponível em: https://www.sciencedirect.com/science/article/pii/S0271530905000248. Acesso em: 25 maio 2021.

KIMURA, Daisuke; CANAGARAJAH, Suresh. Translingual practice. In: JENKINS, Jennifer; BAKER, Will; DEWEY, Martin (ed.). The routledge handbook of English as a lingua franca. [s. I.]: Routledge, p. 295-308, 2018.

KLEIMAN, Angela. Os significados de letramento: uma nova perspectiva sobre a prática social da escrita. Campinas: Mercado das Letras, 1995.

KOCH, Ingedore Villaça. Desvendando os segredos do texto. São Paulo: Cortez, 2003.

KUMARAVADIVELU, Bala. A Linguística aplicada na era da globalização. In: MOITA LOPES, Luiz Paulo. (org.). Por uma linguística aplicada indisciplinar. São Paulo: Parábola, p. 129-148, 2006.

LEROY, Henrique Rodrigues. Dos sertões para as fronteiras e das fronteiras para os sertões: as (in)visibilidades das identidades performativas nas práticas translíngues, transculturais e decoloniais no ensino aprendizagem de Língua Portuguesa Adicional da UNILA. 2018. Tese (Doutorado em Letras) - Universidade Estadual do Oeste do Paraná, Cascavel, 2018.

MIGNOLO, Walter. Local histories/global designs: coloniality, subaltern knowledges and border thinking. New Jersey: Princeton Universit press, 2000.

MOITA LOPES, Luiz Paulo. O português no século XXI: cenário geopolítico e sociolinguístico. São Paulo: Parábola, 2013.

PRATT, Mary Louise. Arts of the contact zone. Profession 91. New York: MLA, p. 33-40, 1991.

ROCHA, Cláudia Hilsdorf; MACIEL, Ruberval Franco. Ensino de língua estrangeira como prática translíngue: articulações com teorizações bakhtinianas. DELTA, São Paulo, v. 31, n. 2, p. 411-445, 2015. Disponível em:

https://www.scielo.br/j/delta/a/yxKXNQQqJPQ3tLPVH9fFyFg/?lang=pt. Acesso em: 01 jun. 2021.

RUTAR, Sonja. Multilingual learning and teaching as a principle of inclusive practice. Journal of Contemporary Educational Studies, [s. I.], v. 1, p. 10-25, 2014. Disponivel em:

https://www.researchgate.net/publication/264860574 Multilingual learning and teachi ng as a principle of inclusive practice. Acesso em: 10 maio 2021.

SANTOS, Milton. Por uma outra globalização: do pensamento único à consciência universal. 6. ed. Rio de Janeiro: Record, 2001.

SHOHAMY, Elana. Democratic assessment as an alternative. Language Testing, London, v. 18, n. 4, p. 373-391, 2001.

SHOHAMY, Elana. Assessing multilingual competencies: adopting construct valid 
assessment policies. The Modern Language Journal, Madison, v. 95, n. 3, p. 418-429, 2011.

SOARES, Magda. Letramento: um tema de três gêneros. Belo Horizonte: Autentica Editora, 2009.

SHOR, Ira. What is critical literacy? Journal of Pedagogy, Pluralism, and Practice, New York, v. 1, n. 4, p. 2-32, 1999. Disponível em:

https://digitalcommons.lesley.edu/jppp/vol1/iss4/2/. Acesso em: 01 junho 2021.

SOUZA, Ana Lúcia Silva. Letramentos de reexistencia: poesia, grafite, música, dança: hip hop. São Paulo: Parábola, 2011.

VERTOVEC, Steven. Super-diversity and its implications. Ethnic and Racial Studies, London, v. 30, n. 6, p. 1024-1054, 2007. Disponível em:

https://www.tandfonline.com/doi/abs/10.1080/01419870701599465?journalCode=rers2 0. Acesso em: 27 junho 2021.

VERTOVEC, Steven. Talking around super-diversity. Ethnic and Racial Studies, London, v. 42, n. 1, p. 125-139, 2019. Disponível em:

https://www.researchgate.net/publication/321580079 Talking around super-diversity. Acesso em: 20 junho 2021.

WEI, Li. Moment analysis and translanguaging space: discursive construction of identities by multilingual Chinese youth in Britain. Journal of Pragmatics, Amsterdam, v. 43, p. 1222-1235, 2011. Disponivel em: https://www.journals.elsevier.com/journal-ofpragmatihttps://www.journals.elsevier.com/journal-of-pragmatics. Acesso em: 01 junho 2021.

Submetido em: 01 out. 2021. Aceito em: 24 out. 2021. 